\title{
Defining the Differences Between Episodic Migraine and Chronic Migraine
}

\author{
Zaza Katsarava • Dawn C. Buse • Aubrey N. Manack • \\ Richard B. Lipton
}

Published online: 15 November 2011

(C) The Author(s) 2011. This article is published with open access at Springerlink.com

\begin{abstract}
Chronic migraine (CM) and episodic migraine (EM) are part of the spectrum of migraine disorders, but they are distinct clinical entities. Population-based studies have shown that those with $\mathrm{CM}$ demonstrate higher individual and societal burden because they are significantly more disabled than those with EM and have greater impaired quality of life both inside and outside the home. Proper diagnosis of both conditions requires clearly defined clinical criteria. Diagnosis enables the initiation of appropriate treatments and risk-factor modification, which ultimately improve functional status and quality of life for persons with migraine. Recognizing that both disorders are on the spectrum of migraine, this review serves as a guide to define the disease state of $\mathrm{CM}$ as distinct from EM in terms of clinical, epidemiological, sociodemographic, and comorbidity profiles.
\end{abstract}

Keywords Chronic migraine - Episodic migraine · Epidemiological profiles $\cdot$ Sociodemographics $\cdot$ Risk factors . Treatment . Chronic daily headache .

Chronification $\cdot$ Diagnosis

\section{Z. Katsarava $(\bowtie)$}

Department of Neurology, University of Essen,

Hufelandstrasse 55,

45122 Essen, Germany

e-mail: Zaza.Katsarava@uk-essen.de

D. C. Buse $\cdot$ R. B. Lipton

Albert Einstein College of Medicine and Montefiore Headache

Center,

Bronx, NY, USA

A. N. Manack

Allergan, Inc.,

Irvine, CA, USA

\section{Introduction}

Migraine is a debilitating headache disorder. Including both episodic and chronic forms, it affects $14 \%$ of the population, and up to $18 \%$ of women [1, 2]. Migraine is currently ranked by the World Health Organization (WHO) as 19th among causes for years lived with disability [1]. Given the current barriers, improving diagnosis and optimizing treatment paradigms could substantially reduce this global burden.

Because there are no biological markers for migraine, diagnosis is based on clinical history and the exclusion of other headache disorders. Health care professionals apply clinical criteria to guide diagnoses and subsequent treatment. The definition of migraine without aura from the second edition of the International Classification of Headache Disorders (ICHD-2) requires all of the following symptoms: a) recurrent headaches (at least 5 lifetime attacks); b) untreated or unsuccessfully treated headache duration of 4 to $72 \mathrm{~h}$; and c) at least two of the following pain characteristics: unilateral, pulsating, moderate or severe intensity, or aggravated by routine physical activity. In addition, the migraine attacks are associated with at least one of nausea/vomiting, photophobia, or phonophobia. Finally, other causes of headache must be excluded [3].

Episodic migraine (EM) is characterized by those with migraine who have 0 to 14 headache days per month, while chronic migraine $(\mathrm{CM})$ is characterized by 15 or more headache days per month. Specifically, revised ICHD-2 (ICHD-2R) criteria define $\mathrm{CM}$ as headache on 15 or more days per month for 3 or more months, of which 8 or more days meet criteria for migraine without aura and/or respond to migraine-specific treatment, occurring in a patient with a lifetime history of at least five prior migraine attacks not attributed to another causative disorder and no medication overuse [4]. 
The relationship between EM and CM is complex. EM progresses to $\mathrm{CM}$ at the rate of $2.5 \%$ per year [5], and $\mathrm{CM}$ often remits to EM (2-year transition rate of 26\%) [6]. The use of a frequency score of 15 or more days per month to classify CM is admittedly somewhat arbitrary. Nonetheless, these clinical definitions identify groups that differ in epidemiologic and symptom profiles, functional consequences and disabilities, indirect and direct costs, patterns of consultation and treatment, and rates of comorbidities. In addition, the patterns of treatment response for EM and CM differ, raising the possibility of both overlapping and distinct biological mechanisms.

Large observational studies have provided valuable information on the distinct clinical characteristics observed in CM and EM $[7 \cdot \bullet, 8 \bullet \bullet, 9,10 \bullet \cdot$. Much of the recently published data that highlight the epidemiological distinction between CM and EM have been generated by three large observational studies: the International Burden of Migraine Study (IBMS), the American Migraine Prevalence and Prevention (AMPP) study, and the German Headache Consortium (GHC) study. IBMS is a web-based, crosssectional, multinational survey that identified and evaluated persons with $\mathrm{CM}$ and persons with EM [7••]. The AMPP study is a large United States (US) population-based, mailbased, longitudinal survey that identified 24,000 respondents with headache and followed them annually for 5 years (2004-2009) [8••]. The GHC study is a German population-based longitudinal survey where respondents completed questionnaires via mail $(n=4642)$ or phone $(n=4708)$ and were identified as either CM, high-frequency EM (9-14 headache $\mathrm{d} / \mathrm{mo})$, or low-frequency EM (0-8 headache $\mathrm{d} / \mathrm{mo})$ and then evaluated on an annual basis [10••].

Herein and with an emphasis on recent key findings, this article provides an update on the similarities and differences between $\mathrm{CM}$ and $\mathrm{EM}$ in their epidemiologic and symptom profiles, functional consequences and disabilities, indirect and direct costs, patterns of consultation and treatment, and rates of comorbidities.

\section{Epidemiology of Chronic Migraine Versus Episodic Migraine}

\section{Prevalence}

Epidemiologic studies in Europe and America estimate that $6 \%$ to $8 \%$ of men and $15 \%$ to $18 \%$ of women experience migraine each year [1]. Recent prevalence data from the US population-based AMPP study reported the 1-year genderstratified prevalence for EM was $17.1 \%$ for women and $5.6 \%$ for men [11], and for CM was $1.3 \%$ for women and $0.5 \%$ for men [12]. CM prevalence rates also varied by age, and were highest for women $(1.9 \%)$ and men $(0.8 \%)$ in the age range of 40 to 49 years. The authors also reported that $\mathrm{CM}$ represents $7.7 \%$ of the total migraine population [12].

Definitional variability of $\mathrm{CM}$ poses an epidemiological challenge; however, a recent systematic review summarizing 12 population-based studies using several definitions for frequent migraine determined the global prevalence of $\mathrm{CM}$ to be from $0.0 \%$ to $5.1 \%$ in the general population, with most estimates in the range of $1.4 \%$ to $2.2 \%[13 \bullet]$. Most of the reviewed studies used the definition of chronic daily headache ( $\geq 15$ headache/mo) with ICHD-1 migraine criteria [14] or the Silberstein-Lipton criteria for CM [15, 16]. None of these criteria matched the current ICHD-2R criteria $[4,13 \bullet]$, at least in part because of difficulties implementing the criteria.

\section{Symptom Profiles}

The IBMS provides the most robust epidemiological data comparing the symptom profiles of CM and EM (Table 1) $[7 \cdot \bullet]$. Findings demonstrated that, on average, persons with $\mathrm{CM}$ had longer duration of headache attacks than those with EM, both treated (24.1 vs $12.8 \mathrm{~h} ; P<0.0001)$ and

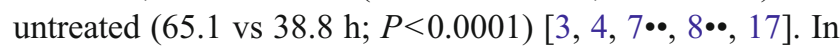
addition, chronic migraineurs were more likely to experience severe pain intensity than episodic migraineurs $[7 \bullet \bullet]$. These population findings are confirmed by clinic-based data. For example, the Phase 3 Research Evaluating Migraine Prophylaxis Therapy (PREEMPT) clinical program [18] characterized 1384 individuals as chronic migraineurs. In a 28-day baseline period, headache occurred on 20 days on average, with 19 migraine days and 18 moderate/severe headache days [18].

\section{Sociodemographics}

The AMPP study and the IBMS demonstrated different sociodemographic findings between persons with EM and CM $[7 \cdot \bullet, 8 \bullet \cdot$. Both studies demonstrated that CM and EM were most common among females in their fourth decade of life, although those with CM were slightly older (AMPP: $\mathrm{CM}=41.7$ y [mean] vs $\mathrm{EM}=40.2$ y [mean], $P=0.005$; IBMS: $\mathrm{CM}=47.7$ y [mean] vs $\mathrm{EM}=46.0$ y [mean], $P=0.03$

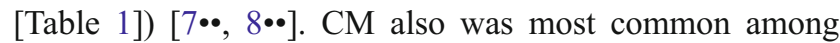

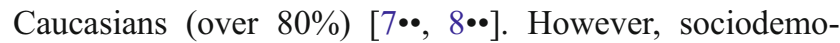
graphic profiles for persons with CM differed from EM in that those with CM reported significantly lower household income levels, were less likely to be employed full time, and were more likely to be occupationally disabled (Table 1) [8••]. In the GHC study, chronic migraineurs also were found to have significantly higher body mass index (BMI; $\mathrm{CM}=25.9$ mean $\mathrm{BMI}$ vs $\mathrm{EM}=24.1$ mean $\mathrm{BMI}, P<0.015$ ), have achieved lower levels of education, and were more likely to be smokers $[10 \bullet \cdot$. 
Table 1 Profiles of persons with chronic migraine and episodic migraine
*Indicates statistical significance $(P<0.05)$ between episodic and chronic migraine

${ }^{a}$ International Classification of Headache Disorders-2 [3]

${ }^{b}$ International Classification of Headache Disorders-2, revised [4]

${ }^{\mathrm{c}}$ Blumenfeld et al. [7••]

${ }^{\mathrm{d}}$ Buse et al. [8••]

${ }^{\mathrm{e}}$ Bigal et al. [17]

${ }^{\mathrm{f}}$ Measured by the Patient Health Questionnaire-9

$B M I$ body mass index, $S D$ standard deviation

\begin{tabular}{|c|c|c|}
\hline Patient profiles & Chronic migraine & Episodic migraine \\
\hline \multicolumn{3}{|l|}{ Clinical characteristics ${ }^{\mathrm{a}, \mathrm{b}, \mathrm{c}}$} \\
\hline Headache frequency, $d / m o$ & $\geq 15$ & $<15$ \\
\hline Severe headache pain, $\%$ & $92.4^{*}$ & 78.1 \\
\hline Duration of headache without medication, mean $h$ & $65.1^{*}$ & 38.8 \\
\hline Duration of headache with medication, mean $h$ & $24.1^{*}$ & 12.8 \\
\hline \multicolumn{3}{|l|}{ Sociodemographics ${ }^{\mathrm{d}}$} \\
\hline Mean age, $y(S D)$ & $47.7^{*}(14.0)$ & $46.0(13.8)$ \\
\hline Race, $\%$ Caucasian & 90.7 & 87.3 \\
\hline Women, $\%$ & 78.6 & 80.0 \\
\hline Occupationally disabled, $\%$ & $20.0^{*}$ & 11.1 \\
\hline Household income, $\%<\$ 22,500 / y$ & $29.9^{*}$ & 24.9 \\
\hline Mean BMI, $n(S D)$ & $29.8(8.3)$ & $29.2(7.9)$ \\
\hline \multicolumn{3}{|l|}{ Resource utilization ${ }^{\mathrm{c}}$} \\
\hline Primary care provider visits, $\%$ & $48.0^{*}$ & 26.4 \\
\hline Neurology/headache specialist visits, $\%$ & $23.8^{*}$ & 8.0 \\
\hline \multicolumn{3}{|l|}{ Comorbidities ${ }^{\mathrm{d}, \mathrm{e}}$} \\
\hline Depression $^{\mathrm{f}} \%$ & $30.2^{*}$ & 17.2 \\
\hline Anxiety, $\%$ & $30.2^{*}$ & 18.8 \\
\hline Obesity, $\%$ & $25.5^{*}$ & 21.0 \\
\hline Cutaneous allodynia, $\%$ & $68.3^{*}$ & 63.2 \\
\hline
\end{tabular}

\section{Individual Burden}

$\mathrm{CM}$ has been shown to impose a greater emotional and social burden on the individual than EM in large observational studies using various validated tools [7••, 9, 19]. Using the Migraine-Specific Quality of Life (MSQ) questionnaire, which details how migraines limit daily performance, the IBMS showed individuals with $\mathrm{CM}$ consistently scoring worse in all categories by 6 to 13 points compared to individuals with EM [7••]. The 2009 AMPP study used the Headache Impact Test-6 (HIT-6) to assess headache impact on the lives of chronic migraineurs [19]. Conversion of HIT6 scores to standard categories revealed that individuals with $\mathrm{CM}$ were much more likely to experience severe headache impact $(72.9 \%)$ than those with EM (42.3\%) [19]. Furthermore, those with $\mathrm{CM}$ had significantly higher odds of adverse headache impact than those with EM (OR 3.5; 95\% CI, 2.77-4.41; $P<0.0001)$ [19]. The AMPP study also evaluated disability and similarly showed that those with $\mathrm{CM}$ had a greater disability according to the Migraine Disability Assessment (MIDAS) questionnaire [9], which calculates a disability score based on reduced productivity (eg, missed days of school and work).

\section{Economic Burden}

In the 2005 AMPP study data, CM respondents had lower household income levels, were nearly twice as likely to be occupationally disabled (CM 20.0\% vs EM 11.1\%; $P<$
0.001), and were less likely to be employed full time than EM respondents (CM 37.8\% vs EM 52.3\%; $P<0.001$ ) [8••]. In the 2006 AMPP study data, more than half of the individuals with $\mathrm{CM}$ missed at least 5 days of household work over a 3-month period, compared with only one quarter of those with EM [9]. Chronic migraineurs were three times more likely to report reduced productivity in household work than those with EM (58.1\% vs $18.2 \%$; $P<$ 0.001) [9]. A minimum of 5 days of missed family activities was reported by $36.9 \%$ of those with $\mathrm{CM}$ and only $9.5 \%$ of those with EM $(P<0.001)$ [9].

In another analysis of the 2005 AMPP study, chronic migraineurs were $19 \%$ less likely to be working for pay and lost $4.6 \mathrm{~h}$ per week from headache compared to $1.1 \mathrm{~h}$ by those with 3 or fewer headache days per month [20]. Although those with high-frequency migraine (10-14 headache $\mathrm{d} / \mathrm{mo}$ ) or CM only accounted for $9.1 \%$ of employed migraineurs, they represented $35 \%$ of the overall lost work time when considering medical leave and unemployment [20]. According to the 2006 AMPP study, those with CM have reported work or school productivity to be reduced by over $50 \%$ in the previous 3 months because of headaches [21].

From a societal perspective, CM is more costly per individual than EM [7••, 21, 22]. Both the AMPP study and IBMS found that those with CM had a statistically significant increase in resource utilization, as evidenced by markedly more primary care visits, specialist visits, emergency room visits, and hospitalizations compared to those with EM [7••, 21, 22]. Regarding US estimates, the 
average per-person annual total costs were more than fourfold greater for those who had progressed to $\mathrm{CM}$ (\$7750) compared with EM (\$1757) [21].

\section{Comorbidities}

Those with various types of migraine share a range of comorbidities. Recent observational studies have provided insight into the distinct comorbidity profiles of those with $\mathrm{CM}$ versus EM. The IBMS demonstrated that those with $\mathrm{CM}$ were significantly more likely to report comorbidities for all groups than EM, notably in nonheadache pain (CM $39.1 \%$ and EM 18.4\%; $P<0.0001)$, psychiatric disorders (CM 46.3\% and EM 28.5\%; $P<0.0001$ ), and vascular disease events (CM 8.2\% and EM 3.3\%; $P<0.0001)$ [7••].

Similarly, the AMPP study $[8 \cdot \bullet$ ] revealed that those with $\mathrm{CM}$ were about twice as likely to be depressed (CM 30.2\% vs EM 17.2\%; OR 2.0; 95\% CI, 1.67-2.40; $P<0.001)$ as determined by self-report on the Patient Health Questionnaire-depression module (PHQ-9) [23] and to have anxiety based on self-report of a physician's diagnosis $(\mathrm{CM}$ $30.2 \%$ vs EM $18.8 \%$; OR $1.8 ; 95 \%$ CI, $1.51-2.15 ; P \leq 0.001$ [Table 1]). Chronic pain disorders also were more than twice as frequent among persons with $\mathrm{CM}(31.5 \%$ vs $15.1 \%$; OR 2.5 ; $95 \% \mathrm{CI}, 2.08-2.97 ; P \leq 0.001)$ as well as specific pain disorders like arthritis (CM $33.6 \%$ vs EM $22.2 \%$; OR 1.7; 95\% CI, 1.43-2.05; $P \leq 0.001)$. In addition, the $\mathrm{CM}$ population also had higher rates of cardiovascular and respiratory comorbidities, such as hypertension, high cholesterol, stroke, emphysema or chronic obstructive pulmonary disease, and asthma $[8 \bullet \bullet$.

\section{Onset and Risk Factors for Progression from Episodic Migraine to Chronic Migraine}

Epidemiological and clinical observations support the progression of EM to CM [24] Progression from EM to CM occurs in about $2.5 \%$ of those with EM annually [5]. Because not all those with EM progress to CM, it is important to identify those at high risk for progression. Risk factors can be broken into two categories: those that are easily modified and those that are not readily modifiable (eg, age, female sex, Caucasian race, low educational level/ socioeconomic status, and head injury) [25]. Identification of modifiable risk factors for progression to $\mathrm{CM}$, such as obesity, depression, and medication overuse, is important because physicians can implement approaches through behavioral and pharmacologic interventions to help the patient maintain a stable, healthy lifestyle, thus reducing the risk of CM [26]. Below are brief discussions of potential modifiable risk factors and their associations with the transition between EM and CM.

\section{Modifiable Risk Factors}

Studies have linked obesity to frequent headache [26]. Although obesity (defined as having BMI $>30$ ) is not a risk factor for the development of EM, it is a risk factor for progression of EM to CM [26]. One large population-based study reported that the prevalence of CM ranged from $0.9 \%$ in normal-weighted persons to $1.6 \%$ in the obese population (OR 1.7 [1.2-2.4]) and $2.5 \%$ in the morbidly obese population (OR 2.2 [1.5-3.2]) [27].

Depression, anxiety, and chronic pain disorders all have been associated with $\mathrm{CM}$ at higher rates than with EM [8••]. It has been difficult to determine the causal relationship between depression and migraine because there is a bidirectional relationship between the two disorders; thus, those experiencing either migraine or depression are at increased risk for developing the other [28]. To explain this relationship, two possible hypotheses are depression as a risk factor for $\mathrm{CM}$ onset or depression as a consequence of $\mathrm{CM}$ [29]. However, recently presented results support a casual rather than consequential relationship between depression and the onset of CM. Adjusted longitudinal modeling of the AMPP study data aimed to assess the role of depression as a predictor of new onset of CM among persons with EM and concluded that, among persons with EM, severe depression was associated with an about 1.28-fold increased risk of the subsequent onset of $\mathrm{CM}$ the following year, even after controlling for factors of headache-related disability and headache-day frequency [29]. Additionally, the effects of depression, anxiety, and obesity are additive, such that migraine-related disability increases when obese individuals have comorbid depression or anxiety compared to nondepressed obese migraineurs [30, 31].

Stressful life events such as divorce, moving, employment changes, or problems with children have been considered a risk factor for chronic daily headache [32]. Results from the frequent headache epidemiology study demonstrated that, compared to episodic headache control patients, those with chronic daily headache had more major life changes in the year before or the same year as the onset of chronic daily headache [32].

Traditionally, acute medication overuse (generally defined as use of medications on more than 10 or $15 \mathrm{~d} / \mathrm{mo}$, depending on the class) [5] has been considered a risk factor for poor migraine prognosis [33, 34]. Recent epidemiological data have shown that intake of (overuse or use of) certain classes of medication increase the risk of $\mathrm{CM}$ in those who already have EM. Specifically, follow-up data from respondents in the 2006 AMPP study demonstrated that those with EM in 2005 had an increased risk of developing $\mathrm{CM}$ when they used compounds that contained barbiturates (OR 2.06; 95\% CI, 1.3-3.1) and opiates (OR 1.98; 95\% CI, 1.4-2.8) [5]. The use of triptans or NSAIDs 
was not associated with increased risk for developing CM [5]. These findings support other population-based [35-37] and clinic-based studies [34] in chronic daily headache.

Another possible risk factor for progression to $\mathrm{CM}$ is the consumption of caffeine. A population-based study that investigated caffeine consumption among participants in a general health survey determined that high medicinal (firstchoice medication containing caffeine) or dietary $(287 \mathrm{mg} / \mathrm{d})$ consumption of caffeine before chronic daily headache onset was a modest risk factor (OR $1.5 ; P=0.05$ ), with an increase in women (OR 1.9; $P=0.006)$ and those who were under 40 years $(\mathrm{OR} 3.4 ; P<0.001)$ [38].

Risk-factor modification, such as decreasing headache frequency with behavioral and pharmacological treatment; weight loss management; avoiding medication overuse and caffeine consumption; and screening and treating depression and other psychiatric comorbidities, remains a component to optimizing care [26].

\section{Patterns of Treatment Response}

\section{Acute Treatment}

Acute medication is often required because migraine attacks are associated with severe and disabling features and usually are accompanied by other symptoms of sensory disturbance (eg, light and sound sensitivity) [39]. Because the clinical distinction between CM and EM is based primarily on the frequency of headache and migraine days rather than the attack features or symptoms, both populations use acute therapies (eg, analgesics and NSAIDs) or migraine-specific agents with vasoconstrictor properties (eg, triptans and ergot derivatives) [9, 39]. Although the patterns of treatment response to acute medication are similar between EM and $\mathrm{CM}$, there are emerging differences driven by the frequency of use, response, and overall satisfaction [9]. It is important to treat $\mathrm{CM}$ and $\mathrm{EM}$ patients at the earliest onset of symptoms; however, those with $\mathrm{CM}$ have a less robust response to triptans than those with EM [40•]. Additionally, medication overuse of acute therapies containing barbiturates and opiates is a risk factor and an important consideration, particularly for CM [5]. It is critical to limit and monitor the use of these compounds when treating migraine and to educate patients on the risks associated with the progression to $\mathrm{CM}$ due to medication overuse.

\section{Preventive Treatment}

As our understanding of the clinical, epidemiological, and pathophysiological differences between EM and CM develops, it becomes highly likely that we will find the patterns of treatment or treatment response to preventive therapies to be different between the two migraine groups. Indeed, the recognition of the two disease states within the ICHD-2 guidelines is designed to facilitate the optimal treatment paradigm and the development of therapies specifically targeted at either EM or CM.

Several classes of drugs are available for migraine prevention, including antihypertensives, antiepileptics, and antidepressants [39]. Specifically, antihypertensive agents available for migraine treatment are $\beta$-blockers, angiotensinconverting enzyme inhibitors, angiotensin receptor blockers, and calcium channel blockers. Common choices of antiepileptics include topiramate, valproate, and gabapentin. In addition, tricyclic antidepressants are commonly used [39].

Many of these therapies also are used in the prevention of CM; however, of the aforementioned EM therapies, only topiramate has demonstrated efficacy in $\mathrm{CM}$ patients through randomized placebo-controlled trials [41, 42]. Additionally, while efficacy has not been demonstrated in EM, onabotulinumtoxin A injections [43] have demonstrated safety and efficacy in $\mathrm{CM}$ patients in randomized, double-blind, placebo-controlled studies [18, 44, 45]. Lessstudied agents in CM preventive treatment include gabapentin, pregabalin, fluoxetine, tizanidine, zonisamide, and memantine [46].

\section{Conclusions}

Migraine is a highly debilitating disease in both its episodic and chronic forms, with the latter imposing more substantial individual and socioeconomic burden as described by various population-based studies $[7 \bullet \bullet, 9,10 \bullet \bullet, 21]$. Through identification of risk factors for progression to $\mathrm{CM}$, clinicians can educate patients about modifiable risk factors and can begin appropriate selected therapy in a timely manner. As research continues to demonstrate, $\mathrm{CM}$ is a distinct disorder with clinico-epidemiological profiles and therapeutic response patterns different from that of EM. Clear definition and enhanced recognition of these two disease states can better facilitate the development of therapies specifically targeted at either EM or CM.

Acknowledgment The authors would like to thank Allergan, Inc. for funding Imprint Publication Science (New York, NY) to provide editorial support in the preparation and styling of this manuscript.

Disclosures Dr. Zaza Katsarava has served as a consultant to Allergan; has received grants or has grants pending from Biogen, Allergan, Merck \& Co., and Bayer; and has received travel expense compensation from Allergan, Biogen, and Novartis. Dr. Dawn Buse has served as a consultant to Allergan, ENDO Pharmaceuticals, Iroko Pharmaceuticals, MAP Pharmaceuticals, Inc., and Merck and Co., and has received grants or has grants pending from Allergan, ENDO Pharmaceuticals, and Merck and Co. Dr. Richard Lipton has served on an advisory board for Allergan, Merck, and MAP Pharmaceuticals; 
has served as a consultant to Allergan; has received grants or has grants pending from GlaxoSmithKline, Allergan, Merck and Co., and Bristol-Myers Squibb; has received payment for manuscript preparation from Allergan; has received payment for the development of educational presentations from Allergan; and had received travel expense compensation from Allergan and Merck and Co. Dr. Aubrey Manack is an employee of Allergan and holds stock interest in the company.

Open Access This article is distributed under the terms of the Creative Commons Attribution Noncommercial License which permits any noncommercial use, distribution, and reproduction in any medium, provided the original author(s) and source are credited.

\section{References}

Papers of particular interest, published recently, have been highlighted as:

- Of importance

•- Of major importance

1. World Health Organization. Headache disorders. Fact sheet $\mathrm{N}^{\circ}$ 277. http://www.who.int/mediacentre/factsheets/fs277/en/. 2004.

2. Stovner LJ, Hagen K, Jensen R, Katsarava Z, Lipton R, Scher A, Steiner T, Zwart JA. The global burden of headache: a documentation of headache prevalence and disability worldwide. Cephalalgia. 2007;27:193-210.

3. Headache Classification Subcommittee of the International Headache Society. The International Classification of Headache Disorders: 2nd edition. Cephalalgia 2004, 24 Suppl 1:9-160.

4. Olesen J, Bousser MG, Diener HC, Dodick D, First M, Goadsby PJ, Gobel H, Lainez MJ, Lance JW, Lipton RB, Nappi G, Sakai F, Schoenen J, Silberstein SD, Steiner TJ. New appendix criteria open for a broader concept of chronic migraine. Cephalalgia. 2006;26:742-6.

5. Bigal ME, Serrano D, Buse D, Scher A, Stewart WF, Lipton RB. Acute migraine medications and evolution from episodic to chronic migraine: a longitudinal population-based study. Headache. 2008;48:1157-68.

6. Manack A, Buse DC, Serrano D, Turkel CC, Lipton RB. Rates, predictors, and consequences of remission from chronic migraine to episodic migraine. Neurology. 2011;76:711-8.

7. •• Blumenfeld A, Varon S, Wilcox TK, Buse D, Kawata AK, Manack A, Goadsby PJ, Lipton RB: Disability, HRQoL and resource use among chronic and episodic migraineurs: Results from the International Burden of Migraine Study (IBMS). Cephalalgia 2011, 31:301-315. This is the only international (nine countries) study of migraine epidemiology. A web-based survey was used to compare those with episodic migraine to those with chronic migraine on headache features, headache-related disability, health-related quality of life, health care resource utilization, and medical and psychiatric comorbidities.

8. .• Buse DC, Manack A, Serrano D, Turkel C, Lipton RB: Sociodemographic and comorbidity profiles of chronic migraine and episodic migraine sufferers. J Neurol Neurosurg Psychiatry 2010, 81:428-432.This population-based study from the United States demonstrates that those with chronic migraine were significantly more likely to have a lower socioeconomic status and more psychiatric/medical comorbidities than those with episodic migraine.
9. Bigal ME, Serrano D, Reed M, Lipton RB. Chronic migraine in the population: burden, diagnosis, and satisfaction with treatment. Neurology. 2008;71:559-66.

10. • Katsarava Z, Manack A, Yoon M-S, Obermann M, Becker H, Dommes P, Turkel C, Lipton RB, Diener HC: Chronic migraine: Classification and comparisons. Cephalalgia 2011, published on January 10, 2011 as doi:10.1177/0333102410383590. This epidemiologic study of a random population in Germany used three different definitions of chronic migraine and demonstrated that the epidemiological profiles of the three groups were similar but differ significantly from those with high- or low-frequency episodic migraine. The prevalence of chronic migraine also differed depending on the definition used.

11. Lipton RB, Bigal ME, Diamond M, Freitag F, Reed ML, Stewart WF. Migraine prevalence, disease burden, and the need for preventive therapy. Neurology. 2007;68:343-9.

12. Reed ML, Buse DC, Manack AN, Fanning KM, Serrano D, Turkel CC, Lipton RB: Prevalence of chronic migraine (CM), headache-related disability and sociodemographic factors in the US population: Results from the American Migraine Prevalence and Prevention (AMPP) study. Headache 2011, 51:28 [abstract P58].

13. - Natoli J, Manack A, Dean B, Butler Q, Turkel C, Stovner L, Lipton R: Global prevalence of chronic migraine: a systematic review. Cephalalgia 2010, 30:599-609. This review article describes the population prevalence of chronic migraine across different populations and explores the various diagnostic criteria for chronic migraine.

14. Headache Classification Committee of the International Headache Society. Classification and diagnostic criteria for headache disorders, cranial neuralgias and facial pain. Cephalalgia 1988, 8 Suppl 7:1-96.

15. Silberstein SD, Lipton RB, Solomon S, Mathew N: Classification of daily and near-daily headaches in the headache clinic. Proposed revisions to the International Headache Society criteria. In Frontiers in Headache Research. Edited by Olesen J. New York: Raven Press, Ltd; 1994:117-126.

16. Silberstein SD, Lipton RB, Sliwinski M. Classification of daily and near-daily headaches: field trial of revised IHS criteria. Neurology. 1996;47:871-5.

17. Bigal ME, Ashina S, Burstein R, Reed ML, Buse D, Serrano D, Lipton RB. Prevalence and characteristics of allodynia in headache sufferers: a population study. Neurology. 2008;70:1525-33.

18. Dodick DW, Turkel CC, DeGryse R, Aurora SK, Silberstein SD, Lipton RB, Diener HC, Brin MF. on behalf of the PREEMPT Chronic Migraine Study Group: OnabotulinumtoxinA for treatment of chronic migraine: Pooled results from the double-blind, randomized, placebo-controlled phases of the PREEMPT clinical program. Headache. 2010;50:921-36.

19. Buse DC, Manack AN, Serrano D, Varon SF, Turkel CC, Lipton RB: Headache impact of chronic and episodic migraine: Predictors of impact from the American Migraine Prevalence and Prevention (AMPP) study. Headache 2011, in press.

20. Stewart WF, Wood GC, Manack A, Varon SF, Buse DC, Lipton RB. Employment and Work Impact of Chronic Migraine and Episodic Migraine. J Occup Environ Med. 2010;52:8-14.

21. Munakata J, Hazard E, Serrano D, Klingman D, Rupnow MF, Tierce J, Reed M, Lipton RB. Economic burden of transformed migraine: results from the American Migraine Prevalence and Prevention (AMPP) study. Headache. 2009;49:498-508.

22. Stokes M, Becker WJ, Lipton RB, Sullivan SD, Wilcox TK, Wells L, Manack A, Proskorovsky I, Gladstone J, Buse DC, Varon SF, Goadsby PJ, Blumenfeld AM. Cost of health care among patients with chronic and episodic migraine in Canada and the USA: results from the International Burden of Migraine Study (IBMS). Headache. 2011;51:1058-77. 
23. Kroenke K, Spitzer RL, Williams JB. The PHQ-9: validity of a brief depression severity measure. J Gen Intern Med. 2001;16:606-13.

24. Bigal ME, Lipton RB. Concepts and mechanisms of migraine chronification. Headache. 2008;48:7-15.

25. Bigal ME, Lipton RB. Modifiable risk factors for migraine progression. Headache. 2006;46:1334-43.

26. Lipton RB. Tracing transformation: chronic migraine classification, progression, and epidemiology. Neurology. 2009;72:S3-7.

27. Bigal ME, Lipton RB. Obesity is a risk factor for transformed migraine but not chronic tension-type headache. Neurology. 2006;67:252-7.

28. Breslau N, Lipton RB, Stewart WF, Schultz LR, Welch KM. Comorbidity of migraine and depression: investigating potential etiology and prognosis. Neurology. 2003;60:1308-12.

29. Ashina S, Serrano D, Lipton RB, Maizels M, Manack AN, Turkel CC, Reed ML, Buse DC: Depression is a risk factor for the transformation of episodic to chronic migraine. Cephalalgia 2011, under review.

30. Vargas BB, Dodick DW. The face of chronic migraine: epidemiology, demographics, and treatment strategies. Neurol Clin. 2009;27:467-79.

31. Tietjen GE, Peterlin BL, Brandes JL, Hafeez F, Hutchinson S, Martin VT, Dafer RM, Aurora SK, Stein MR, Herial NA, Utley C, White L, Khuder SA. Depression and anxiety: effect on the migraine-obesity relationship. Headache. 2007;47:866-75.

32. Scher AI, Stewart WF, Buse D, Krantz DS, Lipton RB. Major life changes before and after the onset of chronic daily headache: a population-based study. Cephalalgia. 2008;28:868-76.

33. Diener HC, Limmroth V. Medication-overuse headache: a worldwide problem. Lancet Neurol. 2004;3:475-83.

34. Katsarava Z, Schneeweiss S, Kurth T, Kroener U, Fritsche G, Eikermann A, Diener HC, Limmroth V. Incidence and predictors for chronicity of headache in patients with episodic migraine. Neurology. 2004;62:788-90.

35. Zwart JA, Dyb G, Hagen K, Svebak S, Holmen J. Analgesic use: a predictor of chronic pain and medication overuse headache: the Head-HUNT Study. Neurology. 2003;61:160-4.

36. Wang SJ, Fuh JL, Lu SR, Liu CY, Hsu LC, Wang PN, Liu HC. Chronic daily headache in Chinese elderly: prevalence, risk factors, and biannual follow-up. Neurology. 2000;54:314-9.

37. Lu SR, Fuh JL, Chen WT, Juang KD, Wang SJ. Chronic daily headache in Taipei, Taiwan: prevalence, follow-up and outcome predictors. Cephalalgia. 2001;21:980-6.
38. Scher AI, Stewart WF, Lipton RB. Caffeine as a risk factor for chronic daily headache: a population-based study. Neurology. 2004;63:2022-7.

39. Goadsby PJ, Sprenger T. Current practice and future directions in the prevention and acute management of migraine. Lancet Neurol. 2010;9:285-98.

40. - Lipton RB, Chu MK: Conceptualizing the relationship between chronic migraine and episodic migraine. Expert Rev Neurother. 2009, 9:1451-1454. This is the first editorial to describe that chronic migraine and episodic migraine are distinct but intimately related disorders.

41. Diener HC, Bussone G, Van Oene JC, Lahaye M, Schwalen S, Goadsby PJ. Topiramate reduces headache days in chronic migraine: a randomized, double-blind, placebo-controlled study. Cephalalgia. 2007;27:814-23.

42. Silberstein SD, Lipton RB, Dodick DW, Freitag FG, Ramadan N, Mathew N, Brandes JL, Bigal M, Saper J, Ascher S, Jordan DM, Greenberg SJ, Hulihan J. Efficacy and safety of topiramate for the treatment of chronic migraine: a randomized, double-blind, placebo-controlled trial. Headache. 2007;47:17080.

43. Naumann M, So Y, Argoff CE, Childers MK, Dykstra DD, Gronseth GS, Jabbari B, Kaufmann HC, Schurch B, Silberstein SD, Simpson DM. Assessment: Botulinum neurotoxin in the treatment of autonomic disorders and pain (an evidence-based review): report of the Therapeutics and Technology Assessment Subcommittee of the American Academy of Neurology. Neurology. 2008;70:1707-14.

44. Aurora SK, Dodick DW, Turkel CC, DeGryse R, Silberstein SD, Lipton RB, Diener HC, Brin MF, on behalf of PREEMPT 1 Chronic Study Group. OnabotulinumtoxinA for treatment of chronic migraine: results from the double-blind, randomized placebo-controlled phase of the PREEMPT 1 trial. Cephalalgia. 2010;30:793-803.

45. Diener HC, Dodick DW, Aurora SK, Turkel CC, DeGryse R, Lipton RB, Silberstein SD, Brin MF, on behalf of the PREEMPT 2 Chronic Migraine Study Group. OnabotulinumtoxinA for treatment of chronic migraine: results from the double-blind, randomized, placebo-controlled phase of the PREEMPT 2 trial. Cephalalgia. 2010;30:804-14.

46. Diener HC, Holle D, Dodick D. Treatment of chronic migraine. Curr Pain Headache Rep. 2010;15:64-9. 